\title{
Correction to: Physical activity and chronic diseases among older people in a mid-size city in China: a longitudinal investigation of bipolar effects
}

Peiling Zhou ${ }^{4^{*}}$, Anne K. Hughes ${ }^{2}$, Sue C. Grady ${ }^{1}$ and Li Fang ${ }^{3}$

\section{Correction to: BMC Public Health 18, 486 (2018) \\ https://doi.org/10.1186/s12889-018-5408-7}

Following publication of the original article [1], the author identified an error in the affiliation of

\section{Reference}

1. Zhou P, Hughes AK, Grady SC, et al. Physical activity and chronic diseases among older people in a mid-size city in China: a longitudinal investigation of bipolar effects. BMC Public Health. 2018;18:486. https://doi.org/10. 1186/s12889-018-5408-7.

- The incorrect affiliation is School of Social Work, Michigan State University, 655 Auditorium Rd., Baker Hall, East Lansing, MI 48824, USA.

- The correct affiliation is: to Harbin Institute of Technology, Shenzhen, China

The author group has been updated above and the original article [1] has been corrected.

\section{Author details}

'Department of Geography, Environment, and Spatial Sciences, Michigan State University, 673 Auditorium Rd., Rm. 203, East Lansing, MI 48824, USA. ${ }^{2}$ School of Social Work, Michigan State University, 655 Auditorium Rd., Baker Hall, East Lansing, Ml 48824, USA. ${ }^{3}$ School of Medicine, Anhui University of Science and Technology, 25 Central Dongshan Rd, Huainan, Anhui 232001 People's Republic of China. ${ }^{4} \mathrm{Harbin}$ Institute of Technology, Shenzhen, China.

Published online: 28 February 2022 regulation or exceeds the permitted use, you will need to obtain permission directly from the copyright holder. To view a copy of this licence, visit http://creativecommons.org/licenses/by/4.0/. The Creative Commons Public Domain Dedication waiver (http://creativeco mmons.org/publicdomain/zero/1.0/) applies to the data made available in this article, unless otherwise stated in a credit line to the data. 